\title{
EU, UM VIDENTE: TRABALHO DE CAMPO ENTRE DANÇAS E SOMBRAS
}

Felipe Moreira ${ }^{1}$

\section{Introdução}

Durante a pós-graduação, me foi apresentada a discussão pós-moderna da antropologia e como ela tem pensado o lugar do 'pesquisador' frente aos seus sujeitos e contexto de campo. Concordando, com algumas ressalvas, claro, em alguns de seus postulados, acredito hoje em sua importância não só para orientar a relação em campo e sua decorrência na escrita, mas na própria formação pessoal/profissional enquanto antropólogos. Reflito aqui sobre o aspecto conformativo do trabalho de campo, não só epistemológico, mas interpessoal. Sendo apenas uma extração da dissertação, as reflexões aqui podem parecer deveras abstratas mas acredito que já servem para pensarmos o campo e o local de fala em um contexto de não-vidência. Sendo a vidência uma narrativa para as pessoas cegas, fica ambígua a relação entre o 'visível e o invisível'. Parafraseando Merleau-Ponty (2012: 15), as perguntas aqui colocadas buscam simular o 'labirinto de dificuldades e contradições' a que ele sobrepõe a fé comum e as "opiniões mudas" das pessoas.

\section{Contextualizando}

Conheci o espetáculo "Desassossego em branco" através da indicação de um colega de curso do mestrado, me informou haver uma bailarina não-vidente que eu poderia contatar para entrevistá-la e conseguir uma inserção no assunto/tema. Assim, ao entrar em contato com ela, fui convidado para ver os ensaios do seu espetáculo que acabava de ganhar um edital para se apresentar durante um ano em algumas cidades de Minas Gerais. A entrevistei, juntamente com o outro membro não-vidente (e um vidente) do projeto, sem pretensões de dar tanta atenção ao espetáculo. Além destas pessoas, entrevistei alguns alunos e alunas cegas da UFMG. Meu contato, então, se deu por estas entrevistas, as vivências entre e pós-ensaio do espetáculo ${ }^{2}$ e trocas de email.

\footnotetext{
${ }^{1}$ Universidade Federal Fluminense, Brasil.

${ }^{2} \mathrm{O}$ espetáculo discute a questão do ver e não-ver, das corporalidades difusas. Sua dinâmica e dança borra os limites do visível e invisível, da transitoriedade. Brincam entre três estados da visão, a perda, o
} 
Tive uma incursão breve com a intenção de pesquisar também o Instituto São Rafael mas por problemas burocráticos, acabei não conseguindo incluí-lo em minha análise pois minha presença ali foi extremamente rápida. Algum tempo já se passou desde as entrevistas/campo (2013), a escrita (final de 2013 e começo de 2014) e meu momento de, agora, voltar um pouco para repensar a parte de campo do meu trabalho para redigir este artigo. Acho interessante como tudo me parece mais interessante agora, revisando minhas notas e relendo minhas asserções. Como denoto mais a frente, o trabalho de campo nem sempre foi prazeroso, muitas vezes era tedioso, gerava preguiça, muitas vezes estava me impedindo de fazer coisas mais divertidas e então eu já partia mauhumorado para o campo. Vários processos e percepções me foram bloqueadas ou mesmo inacessíveis (talvez mesmo “ininventáveis") por conta destas variações humorais. A riqueza parece se mostrar mais reluzente agora e não deixo de pensar que estas dinâmicas, na hora imperceptíveis, aparecem agora depois de uma demorada digestão destas relações difíceis, tanto em razão da minha vivência epistemológica como vidente quanto da dificuldade das relações humanas per se. O que se discute daqui até a conclusão está praticamente intacto, são minhas inquietações como se apresentaram na época do campo e da escrita. Busco avançar um pouco a discussão e trazer uma retrospectiva mais crítica, de acordo com minha vivência hoje e da minha 'visita' a este passado recente mas ainda cercado de sombras Bavcarianas, pois revelam mais através do mistério do que pela ilusão da iluminação.

\section{Eu, um vidente}

Clifford (2011: 18-19) discute como o "presente etnográfico" tem apagado a constituição histórica e política das pessoas que a antropologia buscou estudar, como quem as estagnasse no tempo, facilitando o processo de análise antropológica, já que este não apresentaria problemas de mudança ou incoerências internas se olhados de forma estática. Para ele, é importante termos em mente que o que se está vendo (e descrevendo, por conseguinte) é resultado de ações temporais, políticas e sociais que mudaram, mudam e estão em mudança o tempo todo. Negar isto é uma estratégia autoritária de quem escreve. Concordo em partes com tais críticas, mas acredito que elas

processo de perda e a vidência, sempre alternando, misturando e fusionando estas três etapas. Como discuto melhor no trabalho completo, o público de fato não sabe quem é cego enquanto estão em palco, muitas pessoas inclusive não imaginam que haja ninguém cego ali. 
não se apliquem a todo projeto de pesquisa e escrita. É preciso pensar que dentro de um mesmo grupo as pessoas se dividem e se "oprimem", de certa forma. Não são todos sujeitos que têm poder e voz iguais na constituição de sua própria história e este silenciamento pode ser decorrente de inúmeros fatores como gênero, classe, religião, etc. No caso deste trabalho, penso a não-vidência como um destes fatores de influência na vida dos sujeitos. A visualidade tem um caráter compulsório em nossa sociedade, como argúi em minha dissertação. O raciocínio que se segue é que pessoas sem tal ‘capacidade' não são tidas como 'úteis' para constituição (e certa atuação significativa) da mesma.

Apesar do meu interesse nas discussões pós-modernas, me sinto inseguro para ter alguma 'ousadia' estilística. Ainda vejo minha prática e escrita de forma bastante coesa (e tradicional) com o que aprendi e com o que estou em contato na academia. Sinto certa indecisão entre fazer o que me pedem (ou como interpreto estas relações de poder) e o que realmente quero fazer em termos de escrita e prática antropológica. Não é incomum que em nossos textos recebamos orientações quanto ao corte de certas frases não afirmativas. Mencionar que algum fato poderia ser discutido a luz de uma problemática ou teoria diversa sem detalhar tal afirmação é visto como um complicador e pode levantar questionamentos de seus pares. Assim, uma estratégia recorrente a que somos orientados é de suprimir isto da escrita, por mais que em nosso raciocínio ainda exista essa inferência. Apontar diferentes interpretações (e que divergem da que você está 'oficialmente' escrevendo) sem dar cabo de todas não é uma estratégia recomendada, por mais que elas existam, mesmo que estejam na cabeça mas não na "tinta" do antropólogo. A neutralidade é mais uma pretensão do que um fim a que o aprendizado acadêmico nos prepara:

"Os processos experiencial, interpretativo, dialógico e polifônico são encontrados, de forma discordante, em cada etnografia, mas a apresentação coerente pressupõe um modo controlador de autoridade. Um argumento é que esta imposição de coerência a um processo textual sem controle é agora inevitavelmente uma questão de escolha estratégica." (Clifford, 2011: 55).

A própria experiência e relação social podem ser pensadas enquanto um processo textual (Ibid: 60) e nem mesmo ela me foi possível tratar pela égide da coerência. O meu contato inicial com o grupo foi marginal e eu estava mais interessado na trajetória de vida deles do que na peça em si. Estava encarando o espetáculo apenas como mais dados a serem trabalhados para dar 'corpo' à minha pesquisa. Peguei-me 
interrogando vários colegas de curso e perguntando ao meu orientador qual seria um número aceitável de pessoas a serem entrevistadas de forma que meu trabalho ficasse credível. Por mais leituras pós-modernas que eu estivesse (e pretenda continuar) fazendo, ainda era uma preocupação a aceitação pelos moldes atuais nos quais eu via a prática antropológica. Muito antes de começar a pensar minhas análises enquanto pessoa vidente precisava pensar no meu papel de 'antropólogo' (um substantivo que, se me lembro bem, nunca usei para me auto-referir... gosto de pensar que estudo/faço antropologia, mas não que eu seja 'isto'). Tinha um medo de estar sendo arrogante devido à minha falta de formação e experiência na antropologia, de estar inferindo coisas as quais eu não tinha 'propriedade' para falar. Um, pelo fato desta pesquisa de dissertação ter sido um dos poucos trabalhos a envolver uma relação mais direta com as pessoas das quais escrevia. Dois, por ter sido uma experiência curta e que se mostrou mais rica à análise, ironicamente, meses depois destes contatos quando eu ia revendo minhas anotações e os materiais áudio-visuais disponíveis. O campo, neste momento em que escrevo, mais me serviu como analogia ao material que coletei do que sua fonte principal. Porém, é preciso partir desta discussão de campo para que eu possa pensar na minha inserção sobre o assunto e como sou/fui influenciado de diversas maneiras em minhas percepções e análises das questões aqui propostas.

Outra questão que me surgiu e que também define a natureza das proposições deste trabalho foi um autoaprendizado em relação à escolha do que é 'relevante' ou não para a análise antropológica. Aceitar o fato de que eu tenha pretensões sócio-políticas com este trabalho (e que isto incorra, talvez, de uma visão romantizada sobre a nãovidência) implicou num processo de vigilância maior de minha parte. Fui percebendo uma tendência a achar tudo extremamente interessante, explorável e rico em análise. Nas minhas anotações, pretendia buscar bibliografia para tudo, mesmo que só a estivesse usando para justificar uma escolha arbitrária que às vezes nem eu via tanta importância assim em explorar. Portanto, comecei a tentar ser mais seletivo, até mesmo por conta do tempo/espaço que temos para atender os pré-requisitos de nossas pesquisas. Fui percebendo que separar insights das vivências concretas pode ser algo interessante para nossas pesquisas, por mais que tal afirmação aponte cada vez mais para o processo subjetivo existente na seleção dos fatos 'importantes' ou não nas análises:

"Certamente é difícil dizer muita coisa a respeito de "experiência". Assim como "intuição", ela é algo que alguém tem ou não tem, e sua invocação frequentemente 
cheira a mistificação. Todavia pode-se resistir à tentação de transformar toda experiência significativa em interpretação. Embora as duas estejam reciprocamente relacionadas, não são idênticas. Faz sentido mantê-las separadas, quanto mais não seja porque apelos à experiência muitas vezes funcionam como validações para a autoridade etnográfica." (Ibid: 33)

Esta escolha dos fatos a ser relatados, tal como a forma de abordá-los, é um processo subjetivo que, apesar de ter sua parte racional, é também algo filtrado pela identidade de quem percebe (e consequentemente escreve) e se relaciona com os fenômenos de acordo com sua história:

\begin{abstract}
"A cada momento, meu campo perceptivo é preenchido de reflexos, de estalidos, de impressões táteis fugazes que não posso ligar de maneira precisa ao contexto percebido e que, todavia, eu situo imediatamente no mundo, sem confundi-los nunca com minhas divagações." (Merleau-Ponty, 2011: 5-6).
\end{abstract}

Ao falar sobre a não-vidência, cabe uma ressalva epistemológica sobre a natureza de minhas anotações enquanto pessoa vidente no contato com pessoas cegas já que não só o processo de conhecimento, mas a própria identidade passa por atritos e modificações decorrente deste contato. Isto foi algo perceptível no processo de pesquisa, pois o espetáculo, de dado marginal, passou a configurar praticamente todo o centro de minha análise, me fazendo rever muitas reflexões tomadas por encerradas (expondo inclusive pré-conceitos próprios que eu buscava criticar). Este processo de mudança de perspectivas é importante, pois não só minha relação com o mundo enquanto vidente se modificou profundamente, mas minhas reflexões acerca da nãovidência:

"[...] ethnography is also about the reflective understandings gained through the experiences of the ethnographer, and therefore, in some sense, the ethnographer is not only the teller but an aspect of the telling, and, in the end, of what is told."3 (Creighton, 2006: 414).

Mas, apesar disso, corroboro a visão de que a etnografia é um discurso e um discurso específico e que por mais que a alteridade mude nossas perspectivas, é um exercício interessante estar alerta para que que nossas identidades confluem nossa percepção de mundo e, portanto, continuo sendo um vidente falando sobre pessoas cegas. Por mais que seja possível atingirmos uma percepção aguçada quanto aos

\footnotetext{
${ }^{3}$ Tradução minha: "[...] etnografia é também sobre entendimentos reflexivos adquiridos através da experiência do etnógrafo e, assim, de alguma maneira, o etnógrafo não é apenas o contador mas um aspecto do conto e, no final, do que é contado."
} 
processos discursivos presentes na escrita e estejamos auto-conscientes (nunca por completo) de nosso "local" de fala, não deixamos de cair em outro processo discursivo que apenas muda seus referenciais para ir frente à uma antropologia um pouco mais (pretensiosamente) auto-consciente:

\begin{abstract}
"O discurso não transcende a ocasião específica na qual um sujeito se apropria dos recursos da linguagem para se comunicar dialogicamente. [...] A interpretação não é interlocução. Ela não depende de estar na presença de alguém que fala." (Clifford, 2011: 38).
\end{abstract}

Se minha posição em relação à antropologia pós-moderna parece ambígua em minha fala, não é coincidência, pois minha relação com o pouco que sei dela é está também dividida. Acredito em suas potencialidades para revisarmos criticamente nossos estudos (e os de outrem), mas ao mesmo tempo tenho receio quanto ao uso de sua autocrítica para dar legitimidade ao que dela pode vir a ser criado. Entretanto, as ferramentas que ela nos proporciona para pensar o lugar do discurso e manter a leitora constantemente alerta quanta à natureza deste discurso são úteis para o objetivo do meu trabalho.

Crapanzano (2010), ao discutir os corolários de suas observações sobre o trabalho de campo, disserta a respeito da influência da subjetividade do pesquisador e como sua identidade influencia suas inferências e percepções. Para ele, a constituição identitária de quem pesquisa é pautada por diversas influências e, no nosso encontro com o "novo", atuam de forma a 'afinar' nossas percepções em relação ao que está sendo apresentado, tornando inteligível a relação estabelecida. O encontro com o 'outro' é um encontro também conosco, nos abre para nossos pré-conceitos e orientações, nas palavras do autor: "[...] a mini-drama of plays of power, desire, and imagination."4 (Crapanzano, 2010:58). Desejo e imaginação são coisas que percebo em minhas análises não só pelo que já foi falado acerca das políticas corporais, mas, de certa forma, durante a minha revisão de notas e da minha experiência/vivência com o espetáculo e as pessoas que o compõem, me apercebi de um romantismo ${ }^{5}$ que talvez não fosse

\footnotetext{
${ }^{4}$ Tradução minha: "Um mini-drama de cenas de poder, desejo e imaginação."

${ }^{5}$ Romantismo no sentido de buscar desconstruir a forma como a sociedade vê as corporalidades nãohegemônicas. Talvez meu romantismo me impeça de ver que muitas pessoas tidas como deficientes realmente se sintam coagidas pela sociedade e por mais que minhas "intenções sejam boas", não podemos tirar a autonomia das pessoas em decidirem o que querem e como trilham suas vidas, por mais que acreditemos que o fundo social tem grande influência (muitas vezes negativas) na forma como as pessoas se pensam e agem.
} 
apropriado aos objetivos de uma pesquisa. O contato com discussões sobre fruição estética e emoções no trabalho de campo me ajudou a aceitar mais as minhas idiossincrasias na pesquisa:

"Fieldwork can produce deeply and sometimes troubling emotions in both the anthropologist and his or her informants, who, each in his or her own way, defend against them, say, through repression or by assuming a stoic stance. But fieldwork may also produce pleasurable emotions which we want, sometimes at our expense, to prolong." ${ }^{\circ 6}$ (Crapanzano, 2010: 59)

Estas emoções e estados de ânimo que eu buscava reprimir (como uma má vontade de fazer entrevista ou pesquisa em certos dias, indisposição ou até mesmo tédio em relação à fala das pessoas) se tornaram interessantes para pensar meu posicionamento. Comecei a ficar consciente destas coisas no decorrer do processo e isto também ajudou a pensar as anotações e experiências pós-campo. Percebia meu receio e medo de estar ofendendo ou causando desconforto, do cuidado que eu tinha em elaborar minhas perguntas e conversas para não usar palavras que remetessem à vidência, como "veja bem" ou "como você 'vê' tal questão?". Com o tempo fui me soltando porque percebia que eles mesmos usavam tais palavras. No começo, via isso como uma influência negativa da sociedade, como se ela buscasse suprimir as ressignificações corporais e homogeneizar até a experiência linguística através da compulsoriedade da visão. Porém, me descobri equivocado: “[...] o vocabulário da criança com deficiência visual é fortemente fundamentado na sua própria experiência perceptiva e não simplesmente numa cópia do vocabulário das crianças videntes." (França-Freiras, 2012: 511). Nas entrevistas, as pessoas lidavam sempre com bom humor a qualquer coisa que remetesse à vidência e, ao contrário do que eu pensava, não ficavam relembrando sua experiência de transição para não-vidência de forma dolorosa e sofrível (quando haviam passado por tal transição). Não deixo de me perguntar se isto talvez tenha ocorrido pelo fato de já serem não-videntes há bastante tempo. Será que em outro contexto, por exemplo, pesquisando vivências de pessoas que perderam a visão recentemente, suas falas seriam bastante diversas das que encontrei em campo?

\footnotetext{
6 Tradução minha: "O trabalho de campo pode produzir profundas e algumas vezes problemáticas emoções tanto no antropólogo quanto em seus ou suas informantes, o que, cada um de sua própria maneira, se defende contra elas, digamos, através de repressão ou assunção de um posicionamento estoico. Mas o trabalho de campo também produz emoções prazerosas que queremos, algumas vezes, às nossas custas, prolongar."
} 
A minha própria percepção desse romantismo e alguns pré-conceitos intensificou o meu processo de 'ser afetado' pelo campo, até porque se tratava de um espetáculo artístico e de um processo de fruição. Depois que me percebi tornando o espetáculo parte central da pesquisa, o fato de estar gostando de falar sobre a peça como aporte para uma discussão sobre a não-vidência tornava o processo de escrita prazeroso. Mas ainda me sentia 'menos científico' (por mais que tivesse optado pela antropologia justamente por acreditar que a quantitatividade fosse algo não tão exigido), um por se tratar de uma obra artística e dois por ser algo que me emocionou, como se isto invalidasse minha análise. Pensar nesta questão (permeada pelo dicotomia razão/emoção) me ajudou não só no processo de aceitação enquanto pesquisador mas, também no processo de escrita e compreensão a respeito da agência da arte e a evocação de emoções enquanto algo útil à produção de conhecimento antropológico. A abertura à emoção não é algo meramente estético, mas, principalmente pelo fato de discutir nãovidência e visualidade, pode proporcionar discussões acerca do campo não só enquanto espaço no qual alguém 'adentra' pra capturar alguma reflexão, mas também discussões acerca do campo enquanto espaço sócio-geográfico. O "trabalho de campo" é um exercício em ambas as acepções do termo: exercício de percepção, pois a nossa presença alí permite 'entender' o que se passa, e exercício no sentido de aprendizado/reforço de algo. No contato, tanto com o espetáculo (já que a discussão sobre campo espacial também está presente) quanto no espaço de convivência com as pessoas cegas, há o atrito entre meus entendimentos teóricos e o contato ao vivo com os sujeitos presentes e constituintes destas teorias. Entrar 'em campo' é também estar sujeito a choques e conflitos:

"The "field" itself has strong spatial connotations, and this is one of its merits, even if its physicality has too often been bracketed or seen as simply a backdrop to social life. [...] Entering the field means incorporating a particular sense of place, which is experientially inseparable from the social space, and becoming captured within it often unawares." ${ }^{7}$ (Hastrup, 2010: 192-193)

A discussão sobre a imersão no campo e como o próprio campo nos adentra, juntamente com o uso da emoção enquanto ferramenta, é uma boa estratégia para não

\footnotetext{
${ }^{7}$ Tradução minha: “O 'campo' em si tem fortes conotações espaciais, e isto é um de seus méritos, mesmo que sua fisicalidade tenha sido recorrentemente colocada em segundo plano ou vista como pano de fundo da vida social. [...] Entrar em campo significa incorporar um senso particular de lugar que é experienciado inseparavelmente do espaço social, e ser capturado por ele - geralmente sem perceber.”.
} 
incorrermos nos extremos das análises antropológicas, nem no puro objetivismo nem na pura pós-modernidade relativística. A criação de uma 'poética' para se pensar contextos de produção de conhecimento etnográficos pode nos auxiliar na própria produção destes conhecimentos, como Hastrup se utiliza para falar de sua busca para compreender o campo ártico em seu trabalho através da empatia e da emoção. Mesmo sob a crítica da objetividade, acredito ser interessante ver trabalhos que salientem a subjetividade existente no métier antropológico, pois é através das revisões e contestações que produzimos novos conhecimentos. E se o contato com a alteridade gera emoções que nos inquietam, explorar isso é possibilitar contestações. A emoção também é um dos vetores da mudança. Um auto-questionamento enquanto antropólogo é algo que a curto e longo prazo acrescenta saber à própria teoria, pois ela não nasce do nada e sim por/pelas pessoas em suas relações pessoais, afetivas e acadêmicas (se é que é possível fazer uma separação pura entre tais instâncias). Tratando-se de arte, isto é mais intenso já que a emoção é algo presente em suas expressões. Se se intenta, através de um espetáculo artístico, emocionar a um público através de construções corporais/linguísticas decorrentes das próprias emoções que os artistas sentiram em suas vidas, o fato de que o próprio antropólogo consiga se emocionar, estando ali presente, é sinal de que houve uma experiência significativa, houve empatia:

"[...] the ethnographic — like the poetical — image may be seen as a sudden salience on the linguistic surface, which makes us "recognize" what we did not know. [...] ethnography makes an image of a people out of those images that surround it.". 8 (Ibid: 207).

O que se mostra no espetáculo também são emoções, emoções a mostra, dramatizadas e ritualizadas. Se emocionar é também permitir uma compreensão melhor do que está sendo feito ali, senão, se eu não me emocionasse, extrapolando a máxima cientificista, eu só teria anotações sobre técnicas corporais puras, jogos de luz, musicologia e cenografia para falar. Como desejo discutir pessoas e suas vivências, é necessário se emocionar. $\mathrm{O}$ fato da emoção do contato e da vivência com a alteridade trazer mudanças na forma de pensar do antropólogo é algo que, hoje, influenciado por reflexões como a de Wilkes (2006: 53), vejo como positivo:

\footnotetext{
${ }^{8}$ Tradução minha: “[...] a imagem etnográfica - assim como a poética - pode ser vista como uma repentina saliência na superfície linguística que nos faz 'reconhecer' o que não conhecíamos. [...] a etnografia faz a imagem de um povo através de imagens que o cerca.".
} 
"[...] it is clear that the transformation of the researcher by virtue of immersion in a fieldwork culture is not merely inevitable but desirable, as transformations contribute to the production of meaningful, valid ethnographic knowledge"9.

Apesar de necessárias, estas transformações nem sempre são boas. Minha identidade enquanto vidente, dado o contato com as discussões teóricas, minhas relações no campo e posicionamento político passaram por uma inquietação em relação a minha própria vidência (uma inquietação contínua e potencializada pela forma pessimista como vejo os pré-conceitos corporais e até mesmo me evocando um senso de culpa por "ser" vidente). Apesar de concordar com Crapanzano (2010: 72) quando este diz que "Throughout our fieldwork, we are constantly negotiating our respective identities and our understanding of the situation in which we find ourselves." ${ }^{10}$, dificilmente seria possível, principalmente neste curto espaço de tempo em que convivi com os colaboradores de minha pesquisa, desconstruir a preponderância da vidência em minha vida e percepção de mundo (ou compreender o por quê isto seria necessário). Porém, estas reflexões permitiram entender um pouco da minha própria natureza discursiva. No exercício de tentar perceber o ambiente de acordo com uma perspectiva não-vidente (de forma não pretensiosa já que não me iludo em atingir nem 1\% de como seria tal experiência), fui revendo o meu próprio lugar e minha relação com meu espaço sócio-geográfico. Comecei a compreender a cidade, um ambiente que já não me apreçava democrático, de forma ainda mais excludente. Essa minha abordagem 'pessimista' foi discutida no primeiro capítulo da dissertação já que a teoria também reflete uma escolha localizada discursivamente. Durante a pesquisa, encontrei diversas abordagens à questão das corporalidades não-hegemônicas e fiquei cônscio de que estava pintando um quadro pessimista da relação que os corpos têm no espaço sóciourbano. Até mesmo me percebia irritado ao constatar que as falas nas entrevistas não mostravam essa indignação que eu sentia, ou seja, nas falas das pessoas cegas não havia descontentamento explícito ou raiva em relação a um ambiente que eu acreditava ser hostil (ou talvez não tivesse tido tempo/contato suficiente para que aflorassem).

Até aqui, as reflexões foram mais em um sentido de dividir receios e timidamente traçar um lócus de enunciação. Reitero que não pretendo simular uma

\footnotetext{
${ }^{9}$ Tradução minha: “[...] é transparente que transformações do pesquisador por conta de sua imersão em um trabalho de campo não é algo meramente inevitável, mas também desejável, já que transformações contribuem para a produção de conhecimentos etnográficos válidos e significativos"

${ }^{10}$ Tradução minha: "Durante nosso trabalho de campo, estamos constantemente negociando nossas respectivas identidades e entendimentos das situações nas quais nos encontramos.".
} 
experiência de afetação, como discutida por Favret-Saada (1977), pois nem mesmo a perda da visão me permitiria falar da não-vidência de forma incontestável. A nãovidência não é um fator identitário que aparece de forma destacada nos estudos sobre as corporalidades não-hegemônicas. Para Deshen (1992: 127), por exemplo, a questão da classe social é muito mais marcadora da sociabilidade entre as pessoas cegas do que a própria não-vidência:

“[...] the segregatory force of able-bodied society on blind people may drive some into social niches of their own. But it does not overcome internal categorical differences among blind people. Blindness is not commonly an attribute that leads blind people to associate, but in conjunction with other attributes, it may be."11

Assim, o que me proponho nesta revisitação é pensar o meu lugar de pesquisador/vidente em um campo que se mostra de fato intangível pela experiência epistemológica visual que me caracteriza mas que ao mesmo tempo possibilita pensar os choques entre a minha percepção e a relação com a não-vidência e os não-videntes. $O$ que permeia estas reflexões é o fato de eu ser o representante de um discurso de mundo pautado na visualidade e que, como Belarmino (2009: 184) afirma, não passa de uma ‘ilusão', uma narrativa a ser verifica e relativizada o tempo inteiro na construção de mundo não-vidente. Sendo o discurso vidente uma narrativa que o tempo inteiro é posta em cheque pela experiência sensorial não-vidente, qual o lugar do antropólogo frente a este mundo? E o que a antropologia infere deste contato? Neste aspecto, como ficará mais descritivo no passar deste texto, aproximo a experiência da antropologia com a dança contemporânea para pensarmos o fazer antropológico junto ao processo de fruição e reflexão que o espetáculo traz através de sua dança.

\section{Entre olhares e vivências}

O mais emblemático de estar em 'campo' ao trabalhar a questão da não-vidência é que o retorno para si é quase automático. Era raro algum momento de profunda imersão nas vivências e falas nativas, pois tudo que se era dito causava um estranhamento que, se não analisado na hora de acordo com a minha própria vivência

\footnotetext{
${ }^{11}$ Tradução minha: "[...] a força segregatória de uma sociedade abilitista sobre as pessoas cegas pode direcioná-las a nichos sociais próprios. Mas isto não sobrepõe diferenças categóricas internas entre pessoas cegas. A cegueira não é um atributo comum que leve as pessoas cegas a se associarem, mas em conjunção com outros atributos, pode se tornar.".
} 
vidente, não faria sentido algum e eu perderia ali a riqueza simbólica desta troca de informações. Ao mesmo tempo em que esta situação era confusa pois gerava uma certa desatenção, depois de um tempo foi bastante fértil, mais ainda agora neste momento de retorno algum tempo depois de digerida estas relações. Na hora da convivência era bastante desconfortável até mesmo, pois me perguntava se eu não estaria sendo egoísta ou perdendo o foco de que o que estava em questão ali eram aquelas pessoas e a nãovidência e não eu e minha subjetividade. Mas não faria sentido não atentar para minha subjetividade justamente porque era necessário "filtrar" o que se estava dizendo. Uma aproximação interessante e recente que este fenômeno me causou foi a ideia da epistemologia vidente como uma normatividade que se impõe a nós e fecha nosso horizonte de possibilidades com o mundo.

Fazendo uma aproximação com os estudos de bell hooks (1995) faz todo sentido nos perguntarmos o impacto psicológico, emocional e sensorial que a vidência compulsório nos proporciona e o quanto não só julgamos as demais vivências a partir deste foco mas como treinamos nossas próprias percepções frente às coisas e as pessoas. Le Breton (2011) mostra como os demais sentidos ${ }^{12}$ estão subjugados a visão. Eles estão lá mas sua configuração está limitada ao centro de nosso aparelho visual e ao invés de atuarem como conformadores do mundo, estão na periferia do contato com os fenômenos. Assim como a subjetividade das pessoas negras está a bastante tempo conformado às epistemologias brancas-colonias, sendo necessária uma descolonização da mente, segundo hooks (1995: 474), nossa corporalidade e potencialidades sensoriais estão confinadas ao olhar. E um olhar também colonizado por preceitos de raça, gênero, classe, etc.

Discutir a questão das epistemologias marginais é sempre um trabalho penoso. É comparável ao trabalho criativo de uma escritora que busca extrapolar os limites da sua vivência e, através da uma escrita criativa, criar situações novas, imaginar mundos diferentes. Mas o seu referencial é sempre a sua própria vivência e sua capacidade criativa inventa através das reorganizações de seus referenciais e significações já aprendidas desde a infância. É no encontro consigo mesma que ela se recria. O encontro com a não-vidência partilha de certas premissas da escrita e vivência criativa e deste

\footnotetext{
${ }^{12}$ Segundo Nudds (2004) a ideia de que possuímos apenas 5 sentidos é equivocada. Há muito mais porém nosso 'treinamento' percepto-sensorial baseado nestes cinco e, principalmente na visualidade, nos impede de perceber os limites e alcances das nossas percepções. Muito ainda há para se descobrir e se aventurar neste sentido.
} 
encontro com si. Jorge Luis Borges (2005: 88) nos fala da lenda do Doppelganger. Segundo suas fontes, o doppelganger (também chamado 'o outro') é uma criaturaespelho, é nosso outro-eu, ou um eu-alheio e inverso. É considerado um monstro, pois o contato com ele é mortal. Devemos sempre fugir deste outro-nós, pois o encontro pode ser fatal, mortífero. Mas a morte, nas mitologias, sempre tem uma conotação de mudança, finalização de uma etapa, período, situação, enfim, é a marcação limiar de um rito de passagem.

É esta morte que possibilita este pequeno passo para além das significações, que permite a recombinação de nossos referenciais para adentrar em um território novo, acredito eu. Tanto é que a ideia de 'campo', em 'trabalho de campo' tem uma gênese também visual e territorial. Afinal, em se tratando de antropologia urbana, como no meu caso, quando estou de fato 'em campo' e quando não estou, se transito pelos mesmos espaços que transitei antes de me convencer que 'estou fazendo trabalho de campo'? Para mim, o que define o 'estar em campo' é justamente este afinamento do olhar, da auto-crítica quanto a epistemologia que conforma nossa relação com o mundo e com as pessoas e se assim o é, preciso confrontar este outro-eu e de fato morrer, morrer no incômodo, morrer pela resistência causada pelo choque entre as diferentes assertivas de mundo que ali se chocam. Estar em campo é estar alerta para este encontro, nem sempre agradável e com efeitos tardios, até.

Estudar a não-vidência, estar em 'campo', seja qual campo está ali confluído por territórios distintos é estar alerta às possibilidades de um abismo auto-construído já que o que se confronta é uma alteridade próxima fisicamente da nossa identidade vidente mas ao mesmo tempo está simbolicamente atravessada por distanciamentos que se quer superar mas as vezes só resta a dúvida como alívio. É estar consciente de que os mapas convencionais não trazem alívio e não dá para contar com enraizamento algum pois um terreno que se sustenta em rizomas é sempre escorregadio (Deleuze, 1995).

Por mais que, de fato, o conhecimento avance através de questionamento, estar nesta situação de campo é bastante incômoda. Se enfrenta o status do ver enquanto antropólogo que precisa apreender o não-ver da não-vidência, sem que se ignore a gênese do olhar enquanto conformadora não só da nossa própria percepção mas daquele objeto. Como nos aponta Merleau-Ponty (2012: 18), este movimento de abstração e objetificação é sempre ardiloso, pois na busca pela compreensão além-perceptual em nossas vivências, podemos bagunçar a nossa própria concepção de mundo: 
“[...] se podemos, ainda que o ignoremos, retirar-nos do mundo da percepção, nada nos prova que nele estivemos alguma vez, nem que o observável o seja inteiramente, nem ainda que seja feito de tecido diferente do sonho; uma vez que a diferença entre eles não é absoluta, podemos colocá-los juntos com 'nossas experiências', e é acima da própria percepção que precisamos procurar a garantia e o sentido de sua função ontológica."

Este abismo intransponível entre a percepção vidente da não-vidência (e como de fato superá-la sem se ignorar a vidência em si, mas não contando com ela como ferramenta de apreensão da alteridade) pauta a relação simbólica de interação no campo, ao menos na minha experiência. Afinal, era preciso me atentar não só para um não-ver físico, de um ponto ocular-biológica mas também para o que se 'vê' enquanto materiais de construção que constituiriam nossas subjetividades sobre o mundo através do 'sentir', das sensorialidades mascaradas pela dominação hierárquica da visão sobre os demais sentidos, como apontado acima.

\section{Reflexões finais}

Intentei, ao revisitar o momento do campo e meus escritos de então, pensar como a situação de estar em um campo não-vidente sendo um pesquisador vidente. É um paradoxo interessante de ser explorado, afinal, a ideia de um campo 'que não se pode ver', em um sentido visual, abre uma perspectiva de pensar sobre o processo de encontro das narrativas videntes com a construção de mundo pautada na absorção e reapropriação desta narrativa em acordo com um corpo sensorial não-visual, como Belarmino aponta (2009). Alertar para este paradoxo é ao mesmo tempo buscar explorálo como enriquecedor do campo e não como divisor hierárquico. A diferença constitutiva do campo e explorada pelo pesquisador vidente, ao menos no meu caso, levou a atenção dos intermédios do campo e da diversidade epistêmica-social dos marcadores sociais. A não-vidência entra como uma categoria que, pensada de forma relacional, permite o que Brah (2006: 374) da atenção a compreensão da diversidade para além da dominação ou hierarquização, da diversidade enquanto diferença constitutiva das relações e não constituinte das diferenças de forma desigual. As práticas devem ser compreendidas, e isto inclui a prática etnográfica em uma situação de diferença, quase sempre existente na prática antropológica. 
O que me ocorreu na época e que é reafirmada agora, ao revisitar estes escritos, é o quão significativo foi para mim passar por esta experiência sócio-visual, se assim posso dizer, e ao mesmo tempo estar em contato com a dança contemporânea. A todo o momento que os sujeitos do campo me informavam sobre sua prática artística e de suas vivências sensoriais, me pareciam estar falando de uma coisa só e sempre que diziam 'dança contemporânea', se poderia facilmente trocar esta palavra por 'antropologia'. No relato do espetáculo, afirmavam que não havia um roteiro prévio e que cada espetáculo trazia mudanças, cortes, renovações, extensões, reapropriações, etc. Diziam a respeito de um roteiro nem sólido nem metafísico, funcionando mais para orientar no sentido de dar uma pauta mas sem inibir a criatividade e que permitia o diálogo entre os três membros para repensarem suas práticas no palco e o espetáculo como um todo.

Foi justamente este o desafio aqui, incompleto, como todo bom desafio deve ser: tentar compreender a rudimentalidade destas estruturas de orientação físico-simbólica e os meandros da não-vidência tendo como ponto de partido o meu corpo, constituído pelas expectativas sociais da visualidade que, por sua vez, conformaram minha epistemologia e que não me é possível afastar para captar a riqueza do campo em que me inseri. É necessário então criar uma terceira coisa sem apagar as duas dinâmicas. Na impossibilidade de 'habitar', em um sentido prescrito por Mahmood (2005), esta cosmologia, pensar formas de reorganizar conceitualmente estas relações. É preciso ver uma vantagem neste choque de estar-no-mundo, de daseins tão disitntos. Ir tecendo (Ingold, 2000) as possibilidades destas confluências, somar as epistemologias de forma a esboçar uma metodologia sempre frágil como a estrutura da dança contemporânea, deixando sempre espaço para o inédito, o complexo e o frugal.

\section{Referências}

BELARMINO, Joana de Souza. O que percebemos quando não vemos? Fractal: Revista de Psicologia, vol. 21, no. 1, p. 179-184. Jan./Abr. 2009.

BELL, Hooks. Intelectuais negras. In: Estudos Feministas. Ano 3 n.2. p. 464-478. Rio de Janeiro, 1995.

BORGES, Jorge Luis. El libro de los seres imaginarios. Barcelona, 2005.

BRAH, Avtar. Diferença, diversidade, diferenciação. In: Cadernos Pagu, Campinas, n. 26, 2006, p. 239-276.

CLIFFORD, James. A Experiência Etnográfica: Antropologia e Literatura no século XX. Rio de Janeiro: Editora UFRJ, 2011.

CRAPANZANO, Vincent. "At the Heart of the Discipline": Critical Reflections on Fieldwork. In: DAVIES, James; SPENCER, Dimitrina. Emotions in the Field: The Psychology and Anthropology of Fieldwork Experience. Stanford University Press, 2010. p. 55-78. 
CREIGHTON, Mille. Dancing Lessons from God: To Be the Good Ethnographer or the Good Bad Ethnographer In: GOULET, Jean-Guy; MILLE, Bruce. Extraordinary Anthropology: Transformations in the Field. Lincoln: University of Nebraska Press, 2006. p. 380-417. DELEUZE, Gilles. Mil platôs: capitalismo e esquizofrenia 2, vol. 1. São Paulo, Ed. 34, 1995. DESHEN, Shlomo. Blind People: the private and public life of sightless Israelis. SUNY, 1992. FAVRET-SAADA, Jeanne. Deadly Words: Witchcraft in the Bocage. Cambridge University Press: 1980.

FRANÇA-FREIRAS, Maria Luiza; GIL, Maria Stella. O desenvolvimento de crianças cegas e de crianças videntes. Ver. Bras. Ed. Esp., Marília, v. 18, n. 3, p. 507-526, Jul-Set/2012.

HASTRUP, Kirsten. Emotional Topographies: The Sense of Place in the Far North In: DAVIES, James; SPENCER, Dimitrina. Emotions in the Field: The Psychology and Anthropology of Fieldwork Experience. Stanford University Press, 2010. p. 191-211.

INGOLD, Timothy. The perception of the environment: Essays on livelihood, dwelling and skill. Routledge, 2000.

LE BRETON, David. Antropologia do corpo e modernidade. Petropólis, RJ: Vozes, 2011.

MAHMOOD, Saba. The subject of freedom. In: Politics of piety: the Islamic revival and feminist subject. Princeton: Princeton University Press. 2005.

MERLEAU-PONTY, Maurice. Fenomenologia da percepção. São Paulo: Editora WMF Martins Fontes, 2011.

MERLEAU-PONTY, Maurice. O visível e o invisível. São Paulo: Perpsectiva, 2012.

NUDDS, Matthew.The Significance of the Senses. Proceedings of the Aristotelian Scoiety. Vol. 104, Issue, 1. P. 31-51. June, 2004.

WILKES, Barbara. "Reveal or Conceal?" In: GOULET, Jean-Guy; MILLE, Bruce. Extraordinary Anthropology: Transformations in the Field, Lincoln: University of Nebraska Press, 2006. p. 53-84.

Recebido em: 26/03/2015

Aprovado em: 24/05/2015 